ORIGINAL ARTICLE

\title{
Reviewing the psychological resilience levels of the students studying at the faculty of sports sciences in terms of different variables
}

MUHAMMET BAS ${ }^{1}$, CEMAL GUNDOGDU ${ }^{2}$

${ }^{1}$ Faculty of Sport Sciences, Mus Alparslan University, 49100 Mus, Turkey.m.bas@alparslan.edu.tr

${ }^{2}$ Faculty of Sport Sciences, Inonu University, 44000 Malatya, Turkey. cemal.gundogdu@inonu.edu.tr

Correspondence to: Muhammet Bas, E-mail.m.bas@alparslan.edu.tr

\begin{abstract}
Background: Resilience is a key psychological aspect of sport.

Aim: The purpose of this study was to review the psychological resilience levels of the students studying at faculty of sports sciences in terms of different variables.

Methods: The study was designed in general survey model. The study population was consisted of 670 participants who attended Mus Alparslan University Faculty of Sports Sciences whereas the study sample was consisted of 398 participants. Besides; 162 of the participants were female $(\bar{x} a g e=21.3 \pm 1.9)$ and 236 were male

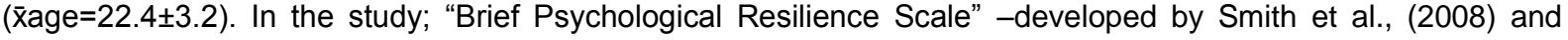
adapted to Turkish by Dogan (2015)- was employed as data collection tool. To analyze the data; such descriptive statistical methods as t-Test and One-Way Analysis of Variance (ANOVA) were used.

Results: It was identified that participants' psychological resilience scale scores differed statistically and significantly on behalf of male participants according to gender variable $(p<0.05)$.

Conclusion: In sum; participants' psychological resilience levels did not differ in terms of the variables of age, academic department, general average academic grades, mother's educational status, father's educational status and grade (class) but it differed on behalf of male participants according to gender variable.

Keywords: Physical education, psychological resilience, sports.
\end{abstract}

\section{INTRODUCTION}

Humans have handled such needs as love, happiness and peace as their basic study case during their life and have thus given numerous terms such as subjective wellbeing, collective self-sufficiency, psychological wellbeing, optimism, internal locus of control, authentic happiness, forgiveness, self-determination, positive aging to psychological world ${ }^{1}$.

Lately; psychological resilience term -derived from the Latin word "resilience"- has been placed in the core of psychology studies. Psychological resilience is one's ability to overcome difficult situations and to adapt himself/herself to these situations ${ }^{2}$. To define psychological resilience correctly; there should be negative and hard life conditions. In positive psychology; that people's strength to recover themselves in a short time after being subjected to intense stress in negative situations and to adapt themselves to normal life quickly is explained as psychological resilience ${ }^{3}$.

Psychological resilience is defined as one's improving and adapting himself/herself even if there may be serious threats that they may face. It emphasizes the process to overcome problems of the past or possible problems of the future, stress sources and risks ${ }^{4}$.

First studies done in psychological wellbeing area focused on individuals and their positive personal qualities like autonomy or high self-esteem but as the number of the studies increased, researchers explored and underlined that psychological resilience is more associated with those factors that are independent from individuals like family structure and social environments ${ }^{5}$. Psychological resilience circle strategy has been designed so that individuals can solve problems, adapt themselves after the solution and continue their developments.
First; there are three steps to improve psychological resilience level;

- To provide interest and support

- To have high expectations

- To provide meaningful participation opportunities.

Following these three steps; there are three more steps in order to reduce risk factor;

- To increase social bonds

- To learn life skills

- To determine clear and consistent boundaries ${ }^{6}$.

Therefore; it is possible to maximize people's psychological resilience by introducing protective factors in time. According to Krovetz's (1999), psychological resilience theory; there are some protective factors in family, school and social circle of the successful individuals and it is thanks to these factors that they can improve psychological resilience skills. As a result; it has been emphasized that people should have some of these protective factors such as social competence, problem solving skills, autonomy, sense of purpose and sense of future in order that they can survive from the difficult situations that they are $\mathrm{in}^{7}$.

Protective factors that influence psychological resilience are those that change the effects of risks in a positive way and promote a healthy adaptation and individual competence ${ }^{8}$. In 2002 Greene and Conrad ${ }^{9}$ argued that protective factors are classified into three groups: individual factors, familial factors and social environmental factors. Werner 1995 too agreed with individual factors (For example; an easy disposition, ability to ask for help when needed even if there is an autonomy), familial factors (For example; supportive parental figure), social environmental factors (For example; presence of a 
teacher that guides and can be taken as a role model). In addition; in the families of the adolescents with high psychological resilience; there is at least one supportive parental figure and furthermore most of them have other social support networks along with that supportive parental figure $^{10}$.

Sports offer both physical and mental competitive settings that fit with the nature of modern life. Since athletes are expected not only to cope with difficult conditions but also to develop themselves in competitive settings created by sports; psychological resilience constitutes a crucial part of sports. Further; university students that study sports sciences have many academic tasks and responsibilities to be completed during their educational period ${ }^{11}$. It is maintained that how these tasks and responsibilities end up is related to psychological resilience levels that individuals have.

In some of the studies in the literature; it was argued that those doing sports demonstrate higher level of psychological resilience ${ }^{12}$. Another study done by Galli and Vealey 2008 concluded that higher level of psychological resilience of those doing sports is associated with their motivational characteristics such as optimism and competitiveness $^{13}$. Sarkar and Fletcher (2014) defined positive personality disposition, motivation, confidence, focus and social support as protective psychological factors for those doing sports ${ }^{14}$.

Lately; studies on sports psychology have been in the increase in our country. It is seen that they are not rich in both method and content. Particularly; closing the gaps in theory will bring new point of views to sports science.

\section{MATERIAL \& METHODS}

Study model: The study was done in general survey model. General survey model is described as a survey study in which the whole population or a sample is surveyed in order to arrive at a general conclusion about the population ${ }^{15}$.

Study Groups: The study population was consisted of 670 participants who attended Mus Alparslan University Faculty of Sports Sciences during 2020-2021 academic year. The study sample was consisted of 398 participants.

Data Collection Tools: In the study; "Information Request form", "Academic Motivation Scale" and "Psychological Resilience Scale" were employed as data collection tools.

Information Request Form: It was designed by the researcher so as to explore participants' demographic properties. It includes questions related to age, gender, academic department, grade, mother's educational status and father's educational status.

Brief Psychological Resilience Scale (BPRS): "Brief Psychological Resilience Scale" -developed by Smith et al., (2008) and adapted to Turkish by Dogan (2015) in order to measure participants' psychological resilience levels- includes six items. 3 items are reversely coded. It is a five point Likert type scale (strongly disagree, disagree, somewhat agree, agree, strongly agree). High scores indicate high level of psychological resilience. The 2nd, 4th and 6th items are reversely coded and internal consistency coefficient of the scale was found to be $0.83^{2}$. In the current study; internal consistency coefficient of the scale was calculated as 0.70 .

Data Analyses: To analyze the data; descriptive statistical methods (percentages/frequencies), One-Way Analysis of Variance (ANOVA) and t-Test were used. $P$ value less than 0.05 was considered statistically significant. Besides; to test reliability of the scales, internal consistency coefficients (Cronbach's Alpha) were calculated and the findings were presented in tables.

Table 1. Frequency and percentage distributions as to participants' demographic characteristics

\begin{tabular}{|c|c|c|c|}
\hline Variables & & $\mathrm{n}$ & $\%$ \\
\hline \multirow{3}{*}{ Gender } & Male & 162 & 40.7 \\
\hline & Female & 236 & 59.3 \\
\hline & Total & 398 & 100.0 \\
\hline \multirow{4}{*}{ Age } & $20 \leq$ & 121 & 30.4 \\
\hline & $21-23$ & 199 & 50.0 \\
\hline & $24 \geq$ & 78 & 19.6 \\
\hline & Total & 398 & 100.0 \\
\hline \multirow{5}{*}{$\begin{array}{l}\text { Academic } \\
\text { Department }\end{array}$} & $\begin{array}{l}\text { Physical Education and Sports } \\
\text { Teaching }\end{array}$ & 72 & 18.1 \\
\hline & Sports management & 100 & 25.1 \\
\hline & Coaching & 106 & 26.6 \\
\hline & $\begin{array}{l}\text { Sports and Exercise for the } \\
\text { Disabled }\end{array}$ & 120 & 30.2 \\
\hline & Total & 398 & 100.0 \\
\hline \multirow{5}{*}{$\begin{array}{l}\text { Grade } \\
\text { (Class) }\end{array}$} & Grade (Class) & 123 & 30.9 \\
\hline & 2. $\quad$ Grade (Class) & 146 & 36.7 \\
\hline & 3. $\quad$ Grade (Class) & 67 & 16.8 \\
\hline & 4. Grade (Class) & 62 & 15.6 \\
\hline & Total & 398 & 100.0 \\
\hline \multirow{4}{*}{$\begin{array}{l}\text { Mother's } \\
\text { Educational } \\
\text { Status }\end{array}$} & Primary School & 214 & 53.8 \\
\hline & Secondary School & 96 & 24.1 \\
\hline & High school and above & 88 & 22.1 \\
\hline & Total & 398 & 100.0 \\
\hline \multirow{4}{*}{$\begin{array}{l}\text { Father's } \\
\text { educational } \\
\text { status }\end{array}$} & Primary School & 152 & 38.2 \\
\hline & Secondary School & 90 & 22.6 \\
\hline & High school and above & 156 & 39.2 \\
\hline & Total & 398 & 100.0 \\
\hline
\end{tabular}

\section{RESULTS}

Table 2. Comparisons of participants' psychological resilience scale scores in terms of gender variable

\begin{tabular}{|c|c|c|c|c|c|c|c|}
\hline \multirow{2}{*}{ Variables } & \multirow{2}{*}{ Gender } & \multirow{2}{*}{ n } & \multirow{2}{*}{$\overline{\mathrm{x}}$} & \multirow{2}{*}{$S S$} & \multicolumn{3}{|l|}{${ }^{t}$ Test } \\
\hline & & & & & & Sd & $p$ \\
\hline \multirow{2}{*}{ Psychological resilience scale } & Female & 162 & 2.96 & 0.611 & -3.33 & 396 & $0.00^{*}$ \\
\hline & Male & 236 & 3.18 & 3.185 & & & \\
\hline
\end{tabular}

${ }^{*} \mathrm{p}<0.05$

When Table 2 was looked at; participants' psychological resilience scale scores were found to differ statistically and significantly on behalf of male participants $(\bar{x}=3.18)$ according to gender variable $(t=-3.33, p=0.00 ; p<0.05)$. 
Table 3. Comparisons of participants' psychological resilience scale scores in terms of age variable

\begin{tabular}{|c|c|c|c|c|c|c|c|c|c|c|}
\hline Variables & Age & n & $\bar{x}$ & sd & Source of variance & Total Square & Sd & Mean Square & $F$ & $p$ \\
\hline \multirow{4}{*}{$\begin{array}{l}\text { Psychological } \\
\text { resilience scale }\end{array}$} & $20 \leq$ & 121 & 3.05 & 0.73 & \multirow{4}{*}{$\begin{array}{l}\text { Inter-group } \\
\text { Intra-group } \\
\text { Total }\end{array}$} & 0.74 & 2 & 0.37 & 0.90 & 0.40 \\
\hline & $21-23$ & 199 & 3.09 & 0.61 & & 164.05 & 395 & 0.41 & & \\
\hline & $24 \geq$ & 78 & 3.17 & 0.54 & & 164.80 & 397 & & & \\
\hline & Total & 398 & 3.09 & 0.64 & & & & & & \\
\hline
\end{tabular}

$\mathrm{p}>0.05$

When Table 3 was investigated; it was found that participants' psychological resilience scale scores did not show a statistical and significant difference in terms of age variable $(F=0.90, p=0.40 ; p>0.05)$.

Table 4. Comparisons of participants' psychological resilience scale scores in terms of academic department variable

\begin{tabular}{|c|c|c|c|c|c|c|c|c|c|c|}
\hline Variables & Academic Department & n & $\bar{x}$ & sd & $\begin{array}{l}\text { Source } \\
\text { of variance }\end{array}$ & \begin{tabular}{|l|} 
Total \\
Square
\end{tabular} & Sd & Mean Square & $F$ & $\mathrm{p}$ \\
\hline \multirow{5}{*}{$\begin{array}{l}\text { Psychological } \\
\text { resilience scale }\end{array}$} & Physical education and sports teaching & 72 & 3.05 & 0.73 & Inter-group & 2.92 & 3 & 0.97 & 2.37 & 0.70 \\
\hline & Sports management & 100 & 3.09 & 0.61 & Intra-group & 164.05 & 394 & 0.41 & & \\
\hline & Coaching & 106 & 3.17 & 0.54 & Total & 164.80 & 397 & & & \\
\hline & Sports and exercise for the disabled & 120 & 3.09 & 0.64 & & & & & & \\
\hline & Total & 398 & & & & & & & & \\
\hline
\end{tabular}

$p>0.05$

Table 4 was investigated and it was identified that participants' psychological resilience scale scores did not yield a statistical and significant difference in terms of academic department variable $(F=2.37, p=0.70 ; p>0.05)$.

Table 5. Comparisons of participants' psychological resilience scale scores in terms of mother's educational status variable

\begin{tabular}{|c|c|c|c|c|c|c|c|c|c|c|}
\hline Variables & Mother's educational status & n & $\bar{x}$ & sd & $\begin{array}{l}\begin{array}{l}\text { Source } \\
\text { of variance }\end{array} \\
\end{array}$ & $\begin{array}{l}\text { Total } \\
\text { Square }\end{array}$ & Sd & $\begin{array}{l}\text { Mean } \\
\text { Square }\end{array}$ & $F$ & $p$ \\
\hline \multirow{4}{*}{$\begin{array}{l}\text { Psychological } \\
\text { resilience scale }\end{array}$} & Primary School & 214 & 3.13 & 0.68 & \multirow{4}{*}{$\begin{array}{l}\text { Inter-group } \\
\text { Intra-group } \\
\text { Total }\end{array}$} & 0.75 & 2 & 0.38 & 0.91 & 0.40 \\
\hline & Secondary School & 96 & 3.08 & 0.54 & & 164.04 & 395 & 0.42 & & \\
\hline & High school and above & 88 & 3.03 & 0.64 & & 164.79 & 397 & & & \\
\hline & Total & 398 & 3.09 & 0.64 & & & & & & \\
\hline
\end{tabular}

$p>0.05$

When Table 5 was investigated; it was seen that participants' psychological resilience scale scores did not give a statistical and significant difference in terms of mother's educational status variable $(F=0.91, p=0.40 ; p>0.05)$.

Table 6. Comparisons of participants' psychological resilience scale scores in terms of father's educational status variable

\begin{tabular}{|c|c|c|c|c|c|c|c|c|c|c|}
\hline Variables & $\begin{array}{l}\text { Father's educational } \\
\text { status }\end{array}$ & $n$ & $\bar{x}$ & sd & $\begin{array}{l}\text { Source } \\
\text { of variance }\end{array}$ & $\begin{array}{l}\text { Total } \\
\text { Square }\end{array}$ & Sd & Mean Square & $\mathrm{F}$ & $p$ \\
\hline \multirow{4}{*}{$\begin{array}{l}\text { Psychological } \\
\text { resilience scale }\end{array}$} & Primary School & 152 & 3.10 & 0.61 & \multirow{4}{*}{$\begin{array}{l}\text { Inter-group } \\
\text { Intra-group } \\
\text { Total }\end{array}$} & 0.24 & 2 & 0.12 & 0.29 & 0.75 \\
\hline & Secondary School & 90 & 3.13 & 0.63 & & 164.55 & 395 & 0.42 & & \\
\hline & High school and above & 156 & 3.06 & 0.68 & & 164.79 & 397 & & & \\
\hline & Total & 398 & 3.09 & 0.64 & & & & & & \\
\hline
\end{tabular}

$p>0.05$

Table 6 was investigated and it was explored that participants' psychological resilience scale scores did not demonstrate a statistical and significant difference in terms of father's educational status variable $(F=0.29, p=0.75 ; p>0.05)$.

Table 7. Comparisons of participants' psychological resilience scale scores in terms of grade (class) variable

\begin{tabular}{|c|c|c|c|c|c|c|c|c|c|c|}
\hline Variables & Grade (Class) & $n$ & $\bar{x}$ & sd & $\begin{array}{l}\text { Source } \\
\text { of variance }\end{array}$ & Total Square & Sd & Mean square & $F$ & $p$ \\
\hline \multirow{5}{*}{$\begin{array}{l}\text { Psychological } \\
\text { resilience scale }\end{array}$} & Grade (Class) & 123 & 3.14 & 0.76 & \multirow{3}{*}{$\begin{array}{l}\text { Inter-group } \\
\text { Intra-group } \\
\text { Total }\end{array}$} & 2.17 & 3 & 0.73 & 1.76 & 0.16 \\
\hline & Grade (Class) & 146 & 3.01 & 0.61 & & 162.62 & 394 & 0.41 & & \\
\hline & Grade (Class) & 67 & 3.09 & 0.50 & & 164.80 & 397 & & & \\
\hline & Grade (Class) & 62 & 3.20 & 0.61 & & & & & & \\
\hline & Total & 398 & 3.80 & 0.64 & & & & & & \\
\hline
\end{tabular}

Table 7 was investigated and participants' psychological resilience scale scores were identified not to have a statistical and significant difference in terms of grade (class) variable $(F=1.76, p=0.16 ; p>0.05)$.

\section{DISCUSSION}

Severe Acute Respiratory Syndrome Coronavirus 2 In this study; participants' psychological resilience scale scores were found to have a statistical and significant difference on behalf of male participants according to gender variable (Table 2).

In the literature, there are studies that support the finding of the current study ${ }^{16,17,18,19,20}$. However; in the literature, there are studies that contradict the finding of the current study, too 21,22,23,24,25,26,27,28,29. Moreover; in the some of studies concluded that participants' psychological resilience levels demonstrated a statistical and significant difference on behalf of female participants. We are of the opinion that the difference was caused by different study groups $30,31,35,36$. 
In this study; it was seen that participants' psychological resilience scale scores did not show a statistical and significant difference in terms of age variable (Table 3). Similarly; the result of the study of Erkoc and Lotfi (2021) concurred with the result of this study ${ }^{26}$. It is thought that age has an effect upon experiences that individuals have during their lives. Yet; it is thought that attitudes that people express towards a negative event occur as a result of their needs and psychological resilience levels. Furthermore; it is thought that today problems of almost all of those who receive university education are similar to each other in some respects; which may have caused psychological resilience levels not to have a statistical difference in terms of age variable.

In this study; it was identified that participants' psychological resilience scale scores did not yield a statistical and significant difference in terms of academic department variable (Table 4). However; the study of Mil (2021) investigated psychological resilience levels among the students who attended physical education and sports teaching and those who attended department of sports management in terms of academic department and reported that psychological resilience levels differed significantly and statistically on behalf of those who attended department of sports management ${ }^{28}$. We are of the opinion that employment opportunities of sports management were worse than physical education and sports teaching. In other words; individuals who study sports management may think that they should struggle more for a better future than those who study physical education and sports teaching. Therefore; it is possible that individuals who study sports management show a higher level of psychological resilience attitude in case of difficulties to be experienced.

In this study; it was seen that participants' psychological resilience scale scores did not give a statistical and significant difference in terms of mother's and father's educational status variable (Table 5-6). In the study of Kandemir (2019); participants' psychological resilience levels did not show a statistical and significant difference in mother's and father's educational status variable ${ }^{30,33}$. However; the study of Gugormus, Okanli and Kocabeyoglu (2015) concluded that participants' psychological resilience levels were not different in mother's educational status while participants' psychological resilience levels were statistically and significantly different in father's educational status on behalf of those participants whose fathers had "university" degrees ${ }^{17}$.

In this study; participants' psychological resilience scale scores were found not to have a statistical and significant difference in terms of grade (class) variable (Table 7). When the literature is investigated, there are studies that concur with the finding of this study ${ }^{16,26,29,30}$. However; in the study of Gurgan (2014) participants' psychological resilience levels demonstrated a statistical and significant difference in grade (class) variable on behalf of those who attend 3rd grades (3rd class) whereas in the study of Can and Cantez (2018) participants' psychological resilience levels showed a statistical and significant difference in grade variable on behalf of those who attend 4th grades (4th class). University students encounter many negative situations and they should overcome them so that they can continue their education. Therefore; it may be concluded that students that attend higher grades (class) show higher level of psychological resilience as compared to those who attend lower grades $24,32,34$.

In sum; it may be suggested that variables of age, academic department, general average academic grades, mother's educational status, father's educational status and grade (class) did not affect participants' psychological resilience levels but male participants had higher level of psychological resilience as compared to female participants.

\section{CONCLUSION}

Institutions that provide education in sports sciences should identify and try to eliminate situations that affect students' psychological resilience levels negatively and provide students with activities that improve their psychological resilience levels. Besides; similar and prospective studies to be done should include more different and bigger sample groups; which will contribute to the literature. Especially; to conduct studies in which both different and similar demographic characteristics are investigated will help the factors that affect psychological resilience be better understood.

\section{REFERENCES}

1. Gable SI, Haidt J. What and why is positive psychology. Review of General Psychology. 2005; 9(2), 103-110.

2. Dogan T. Adaptation of brief resilience scale into Turkish: A validity and reliability study. The Journal of Happiness And Well-Being. 2015;3(1), 93-102.

3. Mandleco BL, Peery JC. An organizational framework for conceptualizing resilience in children. Journal of Child and Adolescent Psychiatric Nursing. 2000;13(3), 99-111.

4. Masten AS. Ordinary magic: Resilience processes in development. American Psychologist.2001;56(3), 227-2.

5. Garmezy N, Masten AS. Stress, competence, and resilience: Common frontiers for therapist and psychopathologist. Behavior Therapy. 1986;17(5), 500- 521.

6. Hawkins JD. Risk and protective factors for alcohol and other drug problems in adolescence and early adulthood: Implications for substance abuse prevention. Psychological Bulletin. 1992;64-105.

7. Krovetz ML. Fosterin resiliency, thrust for educational leadership. 1999;28(5)-28.

8. Albayrak G. A significant concept in positive psychology: psychological resilience, International Journal Of Eurasia Social Sciences. 2018;9:(3), 2492-2505.

9. Greene RR, Conrad AP. Basic assumptions and term. in: Greene RR. Ed. Resiliency: An integrated approach to practice, policy, and research, Nasw Press, Washington DC. 2002;29-62.

10. Werner EE. Resilience in development. Current Directions in Psychological Science. 1995;4(3), 81-84.

11. Eroglu O. Yildirim Y. Determination of academic self-efficacy level of physical education and sport teacher candidate. The Journal of Turkish Sport Science. 2018; 2 (2) , 67-73.

12. Lipowski M, Lipowska M, Jochimek M. Krokosz D. Resiliency as a factor protecting youths from risky behaviour: Moderating effects of gender and sport. European Journal of Sport Science. 2015;16(2), 246-255.

13. Galli N, Vealey RS. Bouncing back from adversity: Athletes' experiences of resilience. Sport Psychologist. 2008;22(3),316-335. 
14. Sarkar M, Fletcher D. Psychological resilience in sport performers: A review of stressors and protective factors. Journal of Sports Sciences. 2014;32(15),1419-1434.

15. Karasar N. Scientific research methods. (8th Ed.) Nobel Press. Ankara. 1994.

16. Aydin I, Oncu E, Akbulut V, Kucuk Kilic S. Phycological resilience and leisure boredom perception in pre-service teacher. Ataturk University, Journal of Physical Education and Sport Sciences. 2019;21(1).

17. Gungormus K, Okanli A, Kocabeyoglu T. Factors influencing resilience in nursing students. Journal of Psychiatric. 2015;6(1),9-14.

18. Hosoglu R, Firinci Kodaz A, Yilmaz Bingol T, Vural Batik M. The resilient levels of preservice teachers. Opus International Journal of Society Researches. 2019;8(14), 217-239.

19. Kilic N, Mammadov M, Kochan K, Aypay A. The predictive power of general self-efficacy beliefs and body images of university students on resilience. Hacettepe University Journal of Education. 2020;35(4),904-914.

20. Tasgin O, Bozgeyikli $\mathrm{H}$, Bogazliyan EE. The relationship between university students' unemployment anxiety and their psychological resilience. HAK-IS International Journal of Labor and Society. 2017;6(16), 551-567.

21. Arslan F, Ayas T. Investigation of psychological strength and forgiveness levels of students receiving religion and psychology education in terms of various variables. Sakarya University Journal of Education Faculty. 2018;(38), 1-29.

22. Aydin M, Egemberdiyeva A. An investigation of university students' resilience levels. Turkey Education Journal. 2018;3 (1),37-53.

23. Damran Akyildirim P. Study of the relationship between selfesteem, perceived social support, and psychological resilience in university students (Master's Thesis). Department of Pyscology, Institute of Social Science, Istanbul Arel University. İstanbul, 2017.

24. Gurgan $U$. The investigation of the resilience and wellness of university students according to some variables. NWSA Education Sciences. 2014;9(1), 19-35.

25. Eroğlu O, Turker A. Examination of the relationship between academic motivation and resilience: $A$ research on individuals receiving postgraduate education in the field of sports sciences. Kuyulu I, Karaca Y. (Ed.), Academic Studies in Sports and Health-1. Ankara: Gece Publishing. 2020;170-191.
26. Erkoc B, Lotfi S. An investigation intended for determining social work students' attitudes towards the ethical dilemma in terms of the psychological resilience levels. Journal of Higher Education and Science. 2021;11(2), 16-16.

27. Karadag TF, Eroğlu O. Investigation of the relationship between psychological resilience and social problem solving: a research on individuals receiving postgraduate education in the field of sport sciences. International Journal of Applied Exercise Physiology. 2020;9(10), 217-229.

28. Toktas S. Examining the levels of forgiveness and psychological resilience of teacher candidates. Journal of Education and Training Studies. 2019;7(4),241-249.

29. Yuksel BO. Investigating the predictive role of alexithymia on loneliness and resilience in university students (Master's Thesis). Department of Pyscology, Institute of Social Science, Yıldız Teknik University. İstanbul. 2019.

30. Kandemir A. An investigation of psychology students in resilience, emotional intelligence and personality features (Master's Thesis). Institute of Social Science, Hasan Kalyoncu University. Gaziantep. 2019.

31. Akdeniz H, Savtekin G, Koylu KI. Examination of the effect of life satisfaction on psychological health levels of university students. Journal of Sport and Recreation Researches, 2021; 36-52.

32. Can M, Cantez KE. Investigation of happiness, resilience and self efficacy levels in university students. Aydın Journal of Humanity and Society, 2018;4(2), 61-76.

33. Ilkım M. Çelik T., Mergan B. Investigation of Sports Management Students' Perceptions and Attitudes towards the COVID-19 Pandemic, Pakistan Journal Of Medical \& Health Sciences, Volume15 Issue 2 Page799-803, 2021

34. Karaca Y., Ilkım M., Investigation Of The Attitudes Distance Education Of The Faculty Of Sport Science Students In The Covid-19 Period, Turkish Online Journal Of Distance Education Volume22, Issue 4, Page114-129,2021

35. Salehian M.H., Sarvari S. The relationship]p between psychological hardiness and resilience and its role in the actual well-being of mothers with handicapped children, Journal of Psychopathology, 2021; 27:163-169

36. Salehian M.H., HemayatTalab A,, Ghanati P. Effectiveness of Qigong Exercises and Resilience Training on the Perceived Stress of Male Students due to Covid-19, Journal of Psychopathology, 2021;Oct 10. DOI: 10.36148/22840249-428 